\title{
Uma proposta de ensino de eletrodinâmica com o método Peer Instruction
}

\section{A Proposal for Electrodynamics Teaching with the Peer Instruction Method}

\author{
I. R. S. MIRANDA1 ${ }^{1}$, C. A. B. S. JÚNIOR*1 \\ ${ }^{1}$ Universidade Federal do Pará.
}

\begin{abstract}
Resumo
Historicamente, o ensino de física apresenta índices alarmantes baseado em microdados do Exame Nacional do Ensino Médio (ENEM), o que faz hoje ele ser pouco atrativo e desmotivador para os alunos. Assim, com o intuito de reduzir tais dificuldades é relevante apresentar uma proposta de ensino complementar por meio de uma sequência didática que envolva Mapa Conceitual (MC), questionário, experimentos e o software circuit lab baseada no método Peer Instruction (Instrução pelos Colegas) nas aulas de Eletrodinâmica. A plataforma Edmodo é usada como ferramenta para auxiliar na avaliação do processo de ensino e aprendizagem dos alunos. A intervenção pedagógica foi realizada por meio de cinco encontros em agosto de 2018 em uma escola da rede privada de ensino no município de Benevides-PA com uma turma diurna de 12 alunos do $3^{\circ}$ ano do ensino médio. A pesquisa desenvolvida é de cunho quanti-qualitativa com atividades diversificadas e constatou que mais de $60 \%$ dos alunos obtiveram rendimento melhorado, além de motivação para buscar conhecer e explorar mais sobre o tema investigado. Foi feita uma analogia e diferença com outros trabalhos. Conclui-se que a proposta obteve bons resultados por facilitar a intermediação do conhecimento e do processo de aprendizagem dos alunos no estudo da Eletrodinâmica.
\end{abstract}

Palavras-chave: Eletrodinâmica. Peer Instruction. circuit lab. Edmodo. Experimentação.

*cabsjr@ufpa.br 


\begin{abstract}
Historically, physics education exhibits alarming rates based on microdata from the national high school exam (NHSE), which today makes it little attractive and demotivator for students. Thus, in order to reduce such difficulties, it is relevant to present a complementary teaching proposal through a didactic sequence that involves concept map (MC), questionnaire, experiments and the circuit lab software based on the Peer Instruction method in the Electrodynamic classes. The Edmodo platform is used as a tool to assist in the evaluation of the teaching and learning process of students. The pedagogical intervention was carried out through five meetings in August 2018 in a private school in the city of Benevides-PA with a day class of 12 students from the 3rd year of high school. The research carried out has quanti-qualitative nature with diversified activities and found that more than $60 \%$ of the students had improved performance, besides the motivation to seek to know and explore more about the investigated topic. An analogy and difference was made with other works. It is concluded that the proposal obtained good results for facilitating students knowledge and learning in the study of electrodynamics.
\end{abstract}

Keywords: Electrodinamics. Peer Instruction. Circuit lab. Edmodo. Experimentation.

\title{
I. INTRODUÇ̃̃O
}

Os relatos de docentes e discentes, atrelados aos resultados de provas institucionais (provas na sala de aula) e de larga escala (Exame Nacional de Ensino Médio - ENEM), mostram um grande déficit na aprendizagem de temas gerais de Física que tem origem desde o Ensino Fundamental e que pode estar associado a diversos fatores, tais como as dificuldades com: representações, manuseio matemático e algébrico das equações Físicas; definições dos conceitos fundamentais e seus significados, pois suas interpretações muitas vezes são baseadas em concepções prévias, resolução de exercícios padronizados, aulas expositivas e desconhecimento de métodos de ensino alternativos (MARCOM, 2015, p.27; OLIVEIRA, ELIANE e ARAUJO, 2015). Nos últimos anos os docentes da área de Ciências e Matemática têm buscado repensar suas práticas na tentativa de motivar os alunos pela busca do conhecimento científico e estimular cada aluno na construção de sua aprendizagem (DELIZOICOV; ANGOTTI; PERNAMBUCO, 2002).

A disciplina de Física parece ser bastante decorativa, por isso monótona, pois o método tradicional de ensino, não os motiva, acaba fazendo com que os alunos acreditem que conhecer fórmulas matemáticas é sinônimo de "saber Física", deixando de lado os conceitos básicos (HAKE, 1998; FREIRE, RICARDO, 2007; CUMMINGS, ROBERTS, 2008). Além disso, ele está fortemente associado com a evasão escolar e a aprendizagem mecânica por parte dos alunos. Diversas são as recomendações abstratas e gerais, de cunho pedagógico, feitas aos professores para reverter esse quadro. Melhorar a formação profissional e acadêmica dos indivíduos nos mais diversos níveis passa por repensar o papel das estratégias formais de ensino (ARAUJO e MASUR, 2013).

A eletrodinâmica é uma parte da eletricidade que se estuda dentro dos conteúdos de Física no Ensino Médio. O ensino da mesma costuma ser bastante confuso e traumatizante 
quando é visto com base apenas em fórmulas, portanto analisando essas queixas, considerase relevante e oportuno criar e utilizar uma sequência didática dinâmica para facilitar a relação de construção do conhecimento e da aprendizagem do tema proposto aos alunos, bem como possibilitar aos professores uma metodologia alternativa e ativa.

Araujo et al. (2017) propôs uma sequência didática no contexto da aprendizagem ativa baseada no método Peer Instruction ou "Instrução pelos Colegas" (IpC) para o ensino de circuitos elétricos em 7 turmas de Ensino Médio Integrado a cursos técnicos. Os resultados mostraram que a sequência didática pode ser utilizada como mediadora da relação ensinoaprendizagem para a discussão de circuitos elétricos.

Para KIELT, da SILVA e MIQUELIN (2017), o Peer Instruction destaca-se pela interatividade entre os participantes, bem como a exigência dos estudantes se tornarem corresponsáveis pelo sucesso da aprendizagem - a aprendizagem ativa. Eles investigaram o desenvolvimento e implementação de um aplicativo para smartphones que realizava o envio de respostas para o notebook do professor durante a resolução de testes conceituais nas aulas.

Atualmente, a perspectiva de ensino por investigação aparece como uma maneira de pensar e repensar a escola e o currículo que reflete a prática pedagógica. Há uma tentativa de envolver os alunos cognitiva e afetivamente, sem lhes dar respostas prontas e prévias, sem conduções muito marcadas pela mão do professor (CACHAPUZ et al., 2011). Nessa perspectiva surgem os seguintes questionamentos: Qual a sequência didática que poderia facilitar consideravelmente o ensino de eletrodinâmica para alunos do ensino médio? Tendo a sequência bem estabelecida, qual a melhor forma de avaliar se a aprendizagem de fato ocorreu?

Sendo assim temos como justificativa dessa pesquisa: (A) a grande dificuldade dos alunos do Ensino Médio em compreender a Eletrodinâmica no cotidiano. (B) a necessidade de uma metodologia de ensino de Física aplicada, alternativa e ativa que exija do aluno ser parte integrante do processo de ensino e aprendizagem.

Visando contribuir para a melhoria do ensino, o presente trabalho tem como objetivo propor uma sequência didática que envolva Mapa Conceitual (MC), questionário, experimentos e o software circuit lab para o ensino-aprendizagem do tema Eletrodinâmica baseada na metodologia Peer Instruction que foi realizada por meio de 5 aulas (encontros) de $50 \mathrm{~min}$. cada nos dias 1, 8, 15, 22 e 29/08/2018 com 12 alunos de uma turma de $3^{\circ}$ ano do Ensino Médio em uma escola de Ensino Fundamental e Médio da rede privada do município de Benevides-PA por meio da plataforma Ed Modo.

\section{FUNDAMENTAÇÃO TEÓRICA}

Para Moreira (2012) a aprendizagem significativa se dá quando há interação entre os conhecimentos prévios e novos. Nesse processo os subsunçores adquirem novos significados, ficando mais ricos e precisos à medida que, os novos conhecimentos complementam a aprendizagem como um todo.

Entende-se que os alunos têm conhecimentos prévios do cotidiano sobre Eletrodinâmica e com a sequência didática proposta faz-se a interação desses conhecimentos, alcançando de forma abrangente, um conhecimento mais amplo sobre o tema. 

dos.

Na visão de Piaget (1972), percebe-se uma pequena diferença na assimilação dos conteú-

[...] a aprendizagem é possível se basearmos a estrutura mais complexa em uma estrutura simples, isto é, quando há uma relação natural de desenvolvimento de estruturas e não simplesmente um reforço externo. [...] uma estrutura desenvolve-se espontaneamente, uma vez alcançado um estado de equilíbrio, ela é duradoura e continuará através de toda a vida da criança. (PIAGET, 1972, p.184).

Ainda para Piaget a aprendizagem da Física está diretamente ligada à experimentação, onde além do seu caráter matemático fundamental, exige-se um lado mais realista e operatório que aprimora a interação do conhecimento externo e interno. Em outras palavras, se faz necessário à construção do conhecimento Físico, as atividades dedutivas e experimentais como pondera Gomes e Bellini (2009).

[...] Este tipo de professor investiga o que o aluno já sabe com a intenção de escolher a melhor prática-didático pedagógica para a sua aprendizagem. Estimula a participação ativa dos alunos na aula através de debates ou de perguntas frequentes, auxiliando-os a saírem de um nível de menor conhecimento para um nível de maior conhecimento. Utiliza diversos tipos de metodologias didático-pedagógicas, pois tem consciência de que os alunos não aprendem todos da mesma maneira. Sugere atividades experimentais desafiadoras, em grupo, incentivando os alunos a formularem as suas hipóteses, discuti-las, testá-las, reformulá-las, até que estejam prontos para darem as suas explicações causais. Apresenta a física como um produto de uma atividade social sujeita às influências política e econômica [...] (GOMES, BELLINI, 2009, p.9).

A partir dessa visão um professor que tem conhecimento da visão de Piaget consegue implementar uma prática mais duradoura e eficaz de forma que o aluno participe ativamente do processo de aprendizagem e consiga ampliar seus horizontes sem estar limitado ao conhecimento do professor. Dessa forma, optamos por utilizar as Metodologias Ativas buscando interligar os conhecimentos dos alunos e acrescentar novos, de modo que cada um apreenda cada tópico ao seu tempo e complemente o saber do outro. Unindo a ideia de Piaget (1972) e Moreira (2012) sobre aprendizagem utilizamos a metodologia Peer Instruction para abordagem do tema Eletrodinâmica, pois entendemos que a construção do saber pode ser aprimorada com essa metodologia ativa.

Para Studart (2019) as Metodologias Ativas são aquelas em que, durante o processo de ensinagem, os alunos participam diretamente do processo, não apenas como ouvintes. Essas metodologias interacionistas têm como foco a descentralização do conhecimento, fazendo com que o aluno seja parte direta, e fundamental, da construção do mesmo. De tal forma que, cada um com seus conhecimentos individuais podem contribuir no desenvolvimento da aula 
trazendo elementos novos, ainda não considerados ou abordados na própria perspectiva do professor (BERBEL, 2011). Segundo Berbel (2011), as metodologias ativas são uma forma de construir o saber utilizando experiências cotidianas ou simuladas. São muitas as metodologias ativas, entretanto as mais conhecidas são: $\mathrm{O}$ estudo de caso, método de projetos, aprendizagem baseada em problemas (PBL), e outras. Cada uma é utilizada de diferentes maneiras, com o mesmo propósito, e mais adequada a cada situação.

Studart (2019) classifica como muito relevantes para os professores de Física as metodologias ativas: Just in Time Teaching (Ensino sob Medida), Peer Instruction (Instrução pelos Colegas - IpC), Aprendizagem Baseada em Problemas (PBL) e os Três Momentos Pedagógicos (3MP).

Por isso, utilizamos a metodologia ativa Peer Instruction (IpC) como fundamental na sequência didática proposta. O método proposto pelo professor Eric Mazur da universidade de Harvard permite que os alunos tenham uma breve explanação teórica do professor que não ultrapasse vinte minutos e em seguida sejam submetidos a um teste conceitual, onde se faz necessária a utilização de um recurso adjacente para isso, como: flashcards, clickers ou ferramentas computacionais (MAZUR, 1997).

O método IpC, descrito por Mazur (1997) e Crouch et al. (2007), pode ser representado mais claramente em nove momentos principais:

1. Breve apresentação oral sobre os elementos centrais de um dado conceito ou teoria é feita por cerca de 20 minutos (min.).

2. Uma pergunta conceitual de múltipla escolha, denominada Teste Conceitual, é colocada aos alunos sobre o conceito (teoria) apresentado na exposição oral.

3. Os alunos têm de 1 a 2 min. para pensar individualmente, e em silêncio, sobre a questão apresentada formulando uma argumentação que justifique suas respostas.

4. Os alunos por meio de um sistema de votação (meios eletrônicos ou clickers, cartões de resposta ou flashcards) informam suas respostas ao professor.

5. De acordo com a distribuição de respostas, o professor pode passar para o passo 6 (quando a frequência de acertos estiver entre 35\% e 70\%), ou diretamente para o passo 9 (quando a frequência de acertos for superior a 70\%).

6. Os alunos discutem a questão com seus colegas por cerca de $2 \mathrm{~min}$.

7. Os alunos votam novamente, de modo similar ao descrito no passo 4 .

8. O professor tem um retorno sobre as respostas dos alunos após as discussões e pode apresentar o resultado da votação para os alunos. Caso o valor ainda permaneça abaixo de $70 \%$ o professor deve optar por discussões em grupos ou revisar o conteúdo apresentado anteriormente, conforme sugere o passo 5.

9. O professor, então, explica a resposta da questão aos alunos e pode apresentar uma nova questão sobre o mesmo conceito ou passar ao próximo tópico da aula, voltando ao passo 1. Essa decisão dependerá do julgamento do professor sobre a adequação do entendimento atingido pelos alunos a respeito do conteúdo abordado nas questões.

A Figura 1 apresenta um diagrama esquemático onde se pode verificar o processo de forma mais simples. 


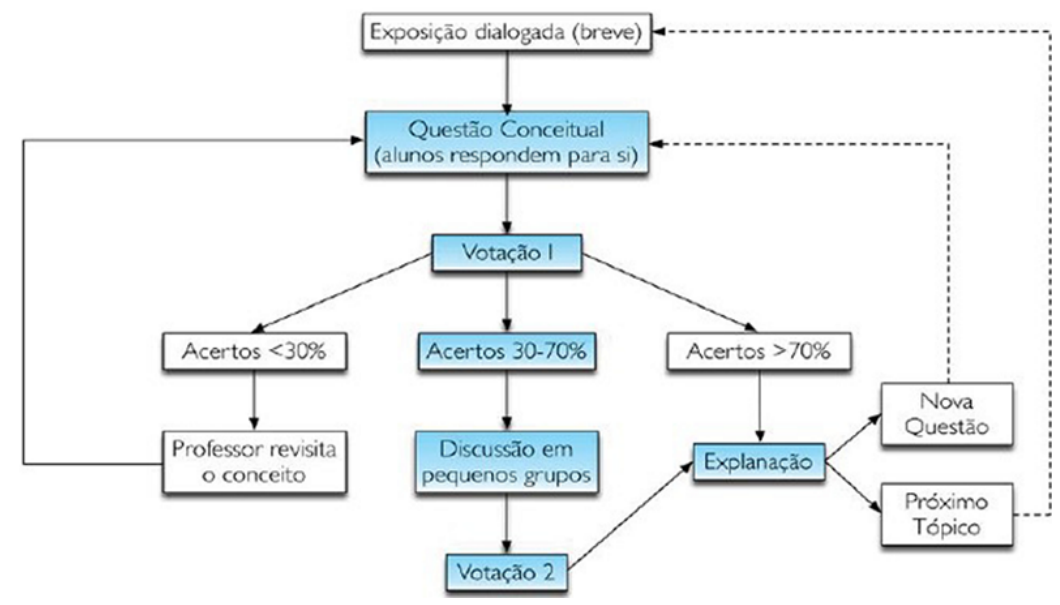

Figura 1: Diagrama esquemático do Peer Instruction (LASRY, MAZUR e WATKINS, 2008).

Dentro desse contexto, surgem ainda as Tecnologias de Informação e Comunicação (TIC's) sendo utilizadas de forma crescente no ensino, seja com a utilização de aplicativos para celulares (KIELT, da SILVA e MIQUELIN, 2017) ou com plataformas educativas como o Moodle (BETANCOURT e PERDOMO, 2008). Em nosso trabalho utilizamos a plataforma Edmodo como ferramenta para auxiliar a divulgação dos materiais e aquisição dos dados das respostas de cada teste realizado. A Figura 2 apresenta uma das perguntas do $1^{\circ}$ teste realizado na plataforma Edmodo pelo aluno 7.
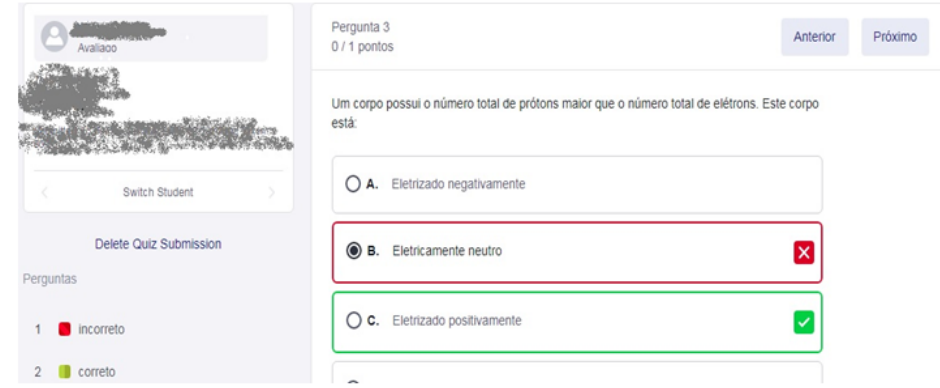

Figura 2: Pergunta 3 do primeiro teste do aluno 7 (Itens hachurados devido a confidencialidade).

Segundo Kielt et al. (2017), durante as discussões em duplas o professor deve transitar pela sala orientando os alunos sobre possíveis dúvidas, sem responde-as, mas sim levando ao pensamento crítico dos mesmos. Isto é, mostrando de forma indireta se o pensamento deles está de acordo ou não com o correto.

\section{METODOLOGIA}

Este trabalho tem como proposta uma pesquisa quanti-qualitativa, pois traz em seu bojo dados matemáticos que produziram resultados quantitativos e busca aprimorar tanto a práxis do professor quanto a construção da aprendizagem pelo próprio aluno. De acordo com Moreira (2010) a pesquisa qualitativa pode apresentar mapas conceituais ou dados que não são autoexplicativos fazendo-se necessário a interpretação e discussão do mesmo 
para melhor entendimento. Além disso, Moreira $(2002,2010)$ também sugere a pesquisaação, pois a mesma tem como objetivo fundamental melhorar a prática em vez de gerar conhecimentos. A produção e utilização do conhecimento se subordinam a este objetivo e estão condicionadas por ele. A melhora na prática consiste em implantar aqueles valores que constituem seus fins, por exemplo, a educação no ensino. Porém, o conceito de educação como fim do ensino transcende a conhecida distinção entre processo e produto. A melhora da prática supõe levar em conta ao mesmo tempo os resultados e os processos.

Dessa forma utilizamos a pesquisa-ação como foco do método, tendo em vista que o objetivo foi adequar à prática comum com um método alternativo. Porém, a pesquisa também tem um caráter quantitativo fundamental, segundo Moreira (2010). Tipicamente, na pesquisa educacional empírica, o pesquisador se questiona sobre qual a evidência que o apoiará em relação a certas hipóteses de pesquisa. Faz, então, registros, converte-os em números e trata-os estatisticamente para ver se servem como evidência. Costuma-se dizer que bons dados falam por si mesmos, isso significa que se os dados forem de boa qualidade os procedimentos estatísticos são imediatos. Por outro lado, se os dados forem ruins não há tratamento estatístico que os transforme em bons.

Os dados obtidos foram filtrados e utilizados como avaliação dos resultados da metodologia aplicada, ou seja, primordiais na regulação da implementação da pesquisa e suporte. Para o desenvolvimento do trabalho foi necessário a estruturação da sequência didática da seguinte forma, como sugere o esquema apresentado na figura 3.

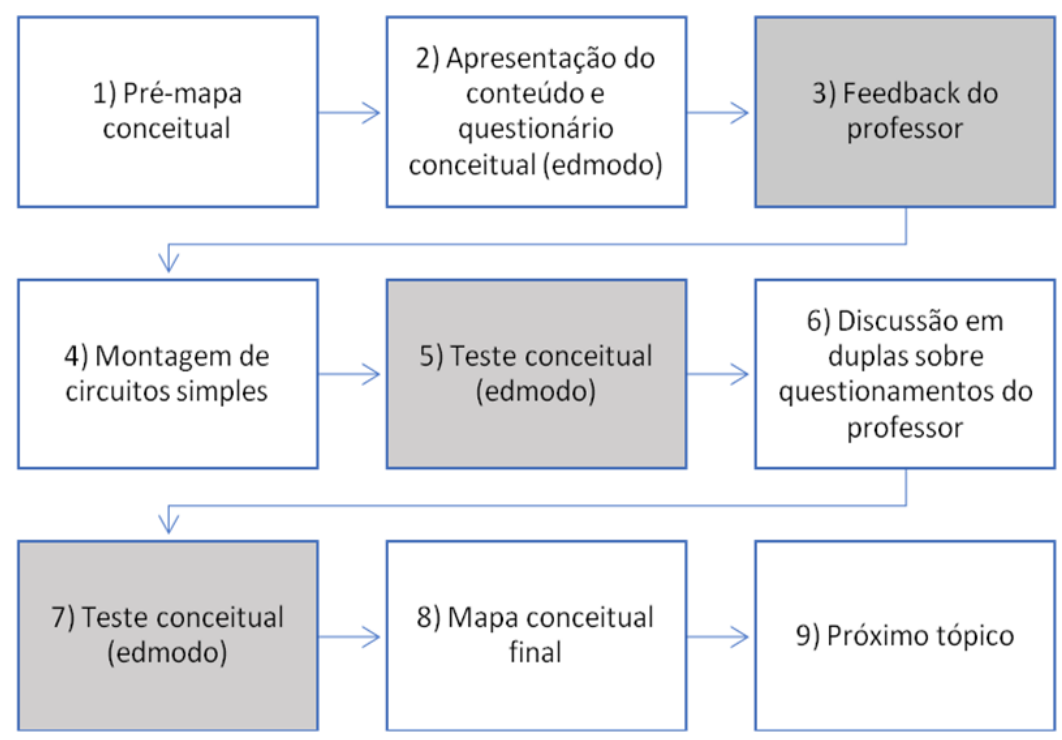

Figura 3: Diagrama de representação da metodologia aplicada.

Nas etapas destacadas na Fig. 3, o professor deve avaliar se deve seguir no processo ou retornar às etapas anteriores até que perceba um resultado satisfatório.

1) os alunos realizarão um "pré-mapa conceitual" apresentando os conhecimentos prévios do tema em questão;

2) através da plataforma Edmodo ${ }^{1}$ os alunos são apresentados a textos e informações iniciais sobre o tema, onde devem fazer leitura e buscar o conhecimento inicial para a

\footnotetext{
${ }^{1}$ Uma plataforma online, rede social, que permite a troca de conhecimentos, criação de turmas online, chats,
} 
discussão e socialização nas aulas seguintes (MAZUR, 1997). Além disso, foram submetidos a pequenos questionários conceituais para avaliar sua "pré-assimilação", ou seja, o que conseguiram assimilar sobre o tema até o momento;

3) o professor faz um feedback (comentário positivo ou negativo) das principais respostas dos alunos nos testes;

4) os alunos são divididos em pequenos grupos ou pares para discutir o que foi apresentado, as vezes instigados por questões ou propostas do professor se necessário;

5) os alunos são submetidos a um novo teste conceitual para avaliar a mudança no conhecimento inicial, aquisição dos conceitos básicos para iniciar a experimentação;

6) a parte experimental surge como uma ferramenta adicional no processo e pretende mostrar no cotidiano dos alunos o que foi estudado. A montagem de pequenos circuitos de resistores em série e paralelo foram propostos para verificar fenômenos importantes como brilho das lâmpadas, diferença de potencial e corrente elétrica em cada um deles;

7) É feito um último teste na plataforma on-line para avaliar o resultado da sequência, consequentemente o aprendizado;

8) para enriquecer os dados obtidos ainda foi proposto, um segundo MC para avaliar os conhecimentos adquiridos pelos alunos após todas as etapas.

A tabela 1 apresenta o cronograma desenvolvido e as práticas de cada encontro.

\begin{tabular}{|c|c|c|}
\hline PERÍODO & PRÁTICA DESENVOLVIDA & ATIVIDADE PROPOSTA \\
\hline $01 / 08 / 2018$ & Avaliação do conhecimento prévio. & Mapa Conceitual (MC). \\
\hline $08 / 08 / 2018$ & Introdução à eletrodinâmica. & Definições de corrente e resistência elétrica, d.d.p., etc. \\
\hline $15 / 08 / 2018$ & Diálogo entre os pares e contextualização. & Instigar sobre os fenômenos do cotidiano ligados ao tema. \\
\hline $22 / 08 / 2018$ & Revisão e Discussão entre os pares. & Revisão dos conteúdos e questionamentos finais. \\
\hline $29 / 08 / 2018$ & Experimentação & Experimentos da $1^{a}$ Lei de Ohm. \\
\hline
\end{tabular}

Tabela 1: Cronograma das atividades e formas de avaliação.

No primeiro dia os alunos se cadastram na plataforma e são apresentados ao tema das próximas aulas pelo professor. Imediatamente após o cadastro os alunos realizaram o primeiro mapa conceitual, apenas com os questionamentos sobre o que seria eletricidade? De que forma podemos entendê-la? E como um "choque" pode gerar energia?

Após, os alunos iniciam as atividades na plataforma com vídeos e textos introdutórios sobre o tema para desenvolver uma ideia inicial. As atividades são realizadas sempre aos pares.

Instigados pelo professor, sempre após a leitura ou visualização dos vídeos com perguntas: o que é uma carga elétrica? O que é uma corrente elétrica? No decorrer do dia os alunos discutem os assuntos e são estimulados a responder as perguntas uns para os outros, gerando assim uma espécie de compartilhamento de conhecimentos e dúvidas.

Na segunda ocasião os temas são apresentados de forma rápida e precisa (de 20 a 25 min) dos conceitos anteriormente estudados, entretanto com o arcabouço matemático e suas aplicações. Novamente os alunos são questionados sobre os conceitos e definições. As atividades ainda são realizadas aos pares e permanecem assim até o fim da metodologia.

questionários e outras ferramentas de fácil utilização. 
Para finalizar o dia os alunos respondem a perguntas teóricas e analíticas na plataforma, além de poderem utilizar das anotações e discussão com o colega. Importante frisar que os alunos não podem acessar a nenhum site de buscas.

No terceiro dia o professor inicia com um problema de eletrodinâmica básico e simples sobre associação de resistores em circuitos elétricos, ver Fig. 4(a) e (b), para explicar sobre o que ocorre com o brilho das lâmpadas em cada caso e o porquê?

(a)

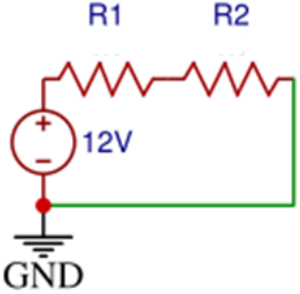

(b)

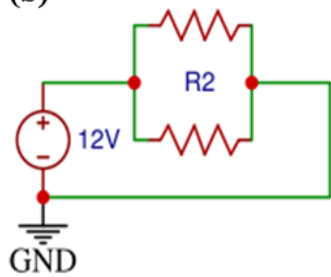

Figura 4: Circuito Elétrico com resistores em (a) série e (b) paralelo produzido no software circuit lab. A sigla GND é o aterramento no circuito. A bateria (pólos $+e-$ ) é de $12 \mathrm{~V}$ e as resistências nos resistores $R 1=R 2=1 k \Omega$.

Com isso os alunos discutiram os tópicos e buscaram definir o que ocorrera com os parâmetros: tensão, corrente elétrica e brilho das lâmpadas. Os circuitos foram obtidos a partir do software circuit lab ${ }^{2}$. Ao final os alunos são submetidos a outro quiz na plataforma para avaliar o decorrido.

No quarto dia foi feita uma breve revisão esclarecendo dúvidas e questionamentos sobre tudo o que foi abordado durante o processo. Os alunos também tiveram a oportunidade de resolver alguns problemas de eletrodinâmica em duplas. No fim do dia, como de costume, realizaram mais uma atividade avaliativa na plataforma.

O quinto dia foi reservado para tratar de experimentos, podendo assim, visualizar o tema no cotidiano. Os experimentos realizados consistem em dois circuitos, contendo: 1 bateria de $12 \mathrm{~V}$, dois resistores (lâmpadas), fios de conexão e um interruptor para ligar e desligar o circuito. O objetivo foi apresentar os esquemas propostos nas figuras 4(a) e 3(b), podendo apreciar na prática o que foi discutido anteriormente. No final do dia os alunos realizaram um novo mapa conceitual para avaliarmos a evolução dos conceitos.

\section{RESULTADOS E DISCUSSÕES}

De acordo com as respostas do questionário levantados na plataforma Edmodo para os 12 alunos, especificados de 1 até 12, obtivemos os seguintes dados que são apresentados na figura abaixo.

\footnotetext{
${ }^{2}$ Software circuit lab é gratuito e serve para produzir os circuitos elétricos. Disponível em: https://www.circuitlab.com/editor /
} 


\begin{tabular}{|c|c|c|c|c|c|}
\hline ALUNO & ATIVIDADE 1 & ATIVIDADE 2 & ATIVIDADE 3 & $\checkmark$ MÉDIA & $\nabla$ \\
\hline & $1\}$ & $30 \%$ \& & $40 \%$ 它 & $75 \% \Rightarrow$ & $48 \%$ \\
\hline & 2 亿 & $25 \%$ 乙 & $40 \%$ 全 & $90 \% \Rightarrow$ & $52 \%$ \\
\hline & $3 \nrightarrow$ & $55 \%$ 仓े & $75 \%$ 全 & $95 \%$ 수 & $75 \%$ \\
\hline & $4 \hat{ن}$ & $75 \%$ 仓 & $80 \%$ 수 & 95\% 순 & $83 \%$ \\
\hline & $5 \nrightarrow$ & $45 \% \Rightarrow$ & $70 \%$ 수 & $100 \%$ & $72 \%$ \\
\hline & $6 \nrightarrow$ & $70 \% \Rightarrow$ & $60 \%$ 全 & $85 \%$ & $72 \%$ \\
\hline & 78 & $15 \% \Rightarrow$ & $55 \%$ 수 & $80 \% \Rightarrow$ & $50 \%$ \\
\hline & $8 \Longleftrightarrow$ & $60 \% \Rightarrow$ & $60 \% \Rightarrow$ & $65 \% \Rightarrow$ & $62 \%$ \\
\hline & $9 \Leftrightarrow$ & 70\% نे & 75\% نे & $75 \%$ نे & $73 \%$ \\
\hline & 10 نे & $75 \%$ 仓े & $75 \%$ 부 & $85 \%$ 누 & $78 \%$ \\
\hline & $11 \hat{ن}$ & 80\% 仓ि & 90\% 분 & 95\% 순 & $88 \%$ \\
\hline & $12 \Longleftrightarrow$ & 70\% 已 & 95\% 순 & 100\% ن & $88 \%$ \\
\hline
\end{tabular}

Figura 5: Dados gerados a partir dos resultados das avaliações na plataforma Edmodo, onde as setas em vermelho, amarelo e verde correspondem aos rendimentos: muito baixo (até $34 \%)$, mediano $(35 \%$ $70 \%$ ) e alto (acima de $71 \%$ ), respectivamente.

A Tabela 1 mostra o resultado das três atividades empregadas no questionário como avaliação feita com os 12 alunos da referida escola na plataforma Edmodo, onde os ganhos, as perdas e a média em cada caso são exibidos. Além disso, podemos verificar as médias de cada aluno onde classificamos de $0 \%$ - 44\% como Insuficiente, 45\% - 79\% como Bom e acima de $80 \%$ ou de $80 \%$ - 100\% como Excelente.

Podemos observar que, na maioria dos casos os alunos demonstraram um aumento no número de respostas certas nos resultados comparado com o número de respostas erradas e prováveis ganhos no conhecimento e na média realizadas nas 3 atividades.

Entretanto, ao longo das Atividades 1 e 2 tivemos os alunos 1 e 2 com rendimento Insuficiente, inferior a 45\%, mas com ganho de 10\% e 15\% na atividade 2 e ganho de 35\% e $50 \%$ na atividade 3 , onde a média foi $48 \%$ e $52 \%$ para os alunos 1 e 2 , respectivamente. Já o aluno 7, dentre todos, teve menor rendimento (15\%) na Atividade 1 aumentando nas Atividades 2 (55\%) e 3 (80\%), ficando com rendimento médio de 50\% nas 3 atividades.

Os alunos 3, 5, 6, 8, 9 e 10 tiveram rendimento Bom na média, entre $45 \%$ e 80\%. Os alunos 3 e 5 foram aumentando os seus rendimentos ao longo das 3 atividades, chegando ao valor máximo de $95 \%$ e $100 \%$ na Atividade 3, cujo rendimento das médias foram $75 \%$ e $72 \%$. O aluno 6 teve diferentes rendimentos ao longo das 3 atividades chegando até a ter uma queda de rendimento na Atividade 2, mas voltou a crescer o rendimento na Atividade 3 obtendo rendimento médio de $72 \%$. Os alunos 8,9 e 10, obtiveram praticamente uma constância nos valores obtidos em pelo menos 2 atividades das 3 realizadas mantendo a média.

Os alunos 11 e 12 foram os que tiveram melhor rendimento nas 3 atividades e na média. O aluno 11 teve maior rendimento na Atividade 1 comparado com o aluno 12, ou seja, 80\% $>70 \%$, porém nas Atividades 2 e 3 o aluno 12 teve maior rendimento que o aluno 1, ou seja, $95 \%>90 \%$ e $100 \%>95 \%$, respectivamente. Entretanto, o rendimento médio dos alunos 11 e 12 foram iguais a $88 \%$.

Porém, destacamos aqui neste trabalho, o pior (48\%) e o melhor $(88 \%)$ rendimento dentre os 12 alunos avaliados, são eles: os alunos 1 e 12. Fazendo uma comparação entre os dois ao longo das 3 atividades desenvolvidas, temos que o aluno 12 tem um rendimento maior do 
que o aluno 1 nas 3 atividades, como podemos citar aqui de 40\%, 55\% e 25\% nas Atividades 1,2 e 3 respectivamente, enquanto que o aumento no rendimento com relação a média foi de $40 \%$.

Sabemos que as atividades desenvolvidas na plataforma Edmodo não devem ser os únicos avaliadores de aprendizagem e tão pouco, são suficientes para caracterizar o aprendizado. Dessa forma, além das avaliações em sala, utilizamos também os mapas conceituais (MCs), ver Fig. 5 e 6. Os MCs foram transcritos na íntegra, pelos alunos com o auxílio do professor (mediador), para o software cmap tools para facilitar a compreensão e organização do trabalho. Reforçamos que nenhuma informação foi acrescentada e nem removida dos mesmos.

Para exemplificar os resultados obtidos com os MCs aplicados antes e depois das 3 atividades vamos comparar o desempenho dos alunos 1 e 12 que são, respectivamente, os de pior e melhor desempenho geral.

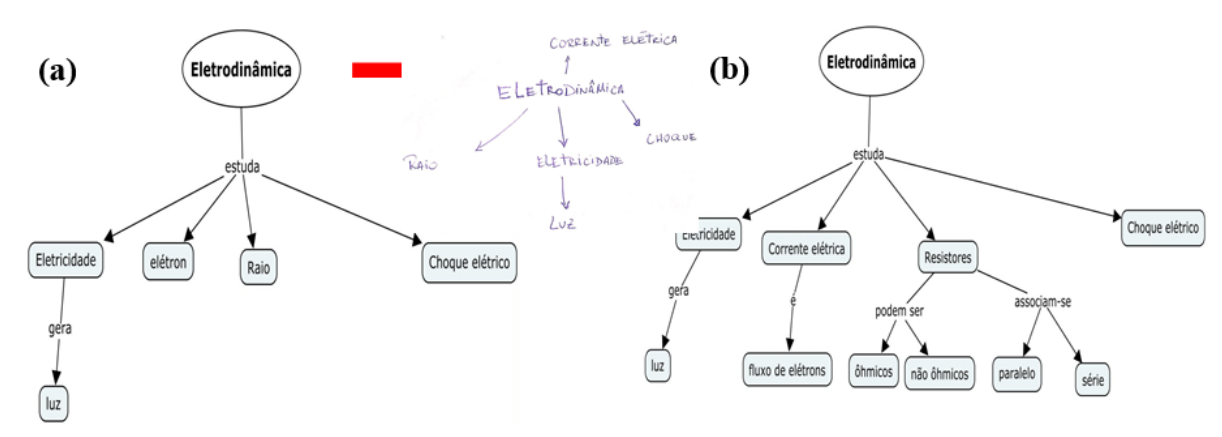

Figura 6: Mapa Conceitual (MC) com o software cmap tools do Aluno 1 aplicado (a) antes e (b) depois. No centro de caneta o MC antes das 3 atividades.

Na Fig. 5 (a) e (b) é possível perceber que o aluno 1 obteve um considerável ganho conceitual sobre o tema. Apesar de não ser ideal, obtivemos um resultado considerável e uma diferença significativa entre os dois mapas, (a) antes e (b) depois. O aluno 1 demonstrava pouco interesse nas aulas e não desenvolvia todas as atividades propostas. Apesar disso, e com o auxílio dos outros alunos (colegas de turma) começou a participar mais das atividades e apresentou um ganho considerável em pouco tempo nas outras 2 atividades (10\% e 45\%).

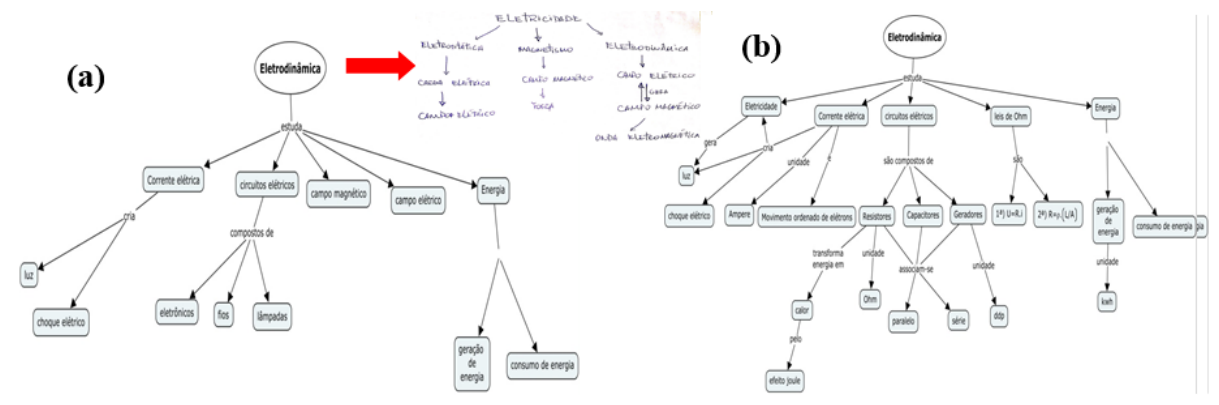

Figura 7: MC com o software cmap tools do Aluno 12 aplicado (a) antes e (b) depois. No centro de caneta o MC antes das 3 atividades.

Na Fig. 5(a), o aluno 12 apresentou conhecimentos iniciais evoluídos sobre o assunto e percebeu-se que o seu MC apresentou mais informações e ligações após as atividades 
desenvolvidas, ver Fig. 5(b). Obviamente o MC não está conceitualmente completo nem tão pouco ideal, porém apresenta boa parte dos conteúdos tratados. Apesar disso, o MC traz alguns erros conceituais aceitáveis.

Durante o processo algumas falas dos alunos chamaram atenção, principalmente dos alunos 7 e 12. O aluno 7 não apresentava interesse pelas aulas de física, pois segundo ele:

Aluno 7: "É uma disciplina que eu nunca vou usar...Tem muitas coisas sem sentido e um monte de fórmulas que tenho que decorar!"

Durante as atividades, em dupla, o aluno começou a discutir sobre o tema no cotidiano, questionar fenômenos físicos, e interagir com as propostas.

Aluno 7: "Por que os raios caem no para-raios e não nos prédios? Por que eles acertam árvores, não deveriam acertar somente metais?"

Ao final das atividades o aluno mostrou-se muito mais motivado com as aulas de Física e a metodologia IpC empregada. Aluno 7: "Professor, o senhor deveria fazer todas as aulas desse jeito. Aprendemos uns com os outros... agora eu acho que a Física realmente serve pra alguma coisa."

O Aluno 12 já demonstrava interesse pela disciplina e principalmente pelo tópico, entretanto achou bastante interessante a metodologia utilizada.

Aluno 12: "Eu imaginava que a aula seria uma apresentação no 'datashow' seguida de vários exercícios de vestibulares. Mas, me surpreendi acredito que as aulas fluem melhor quando vemos sentido no que estamos estudando, quando são coisas que conhecemos, do dia a dia."

Em geral, os alunos disseram está mais interessados pelas aulas de Física. Os resultados mostraram que o rendimento aumentou em todos os casos, mostrando-se uma metodologia eficaz.

Os autores Araújo et al. (2017) sugerem o método Peer Instruction de forma similar em um trabalho com circuitos elétricos no qual utilizam outra ferramenta de software livre. Aqui apresentamos a proposta da plataforma Edmodo por se tratar de um Ambiente Virtual de Aprendizagem (AVA) onde o professor não se limita apenas em propor atividades, mas também, tem maior liberdade em introduzir textos, perguntas, vídeos, entre outras coisas relacionadas com o tema em questão. Muito similar a uma rede social, porém com propósito educacional, podendo ainda incluir os pais dos alunos nas turmas criadas.

\section{CONCLUSÃo}

Segundo Araujo et al. (2017), trabalhos publicados nas últimas décadas apresentaram aplicações de metodologias alternativas, capazes de modificar a estrutura de uma aula tradicional de física. As estratégias de aprendizagem ativa têm se destacado na literatura internacional, sendo apresentadas como opções viáveis para implantação no Ensino Médio. Elas permitem maior engajamento dos alunos, utilizando um estudo prévio, observação de fenômenos físicos e interpretação de testes conceituais.

A metodologia Peer Instruction (IpC) se mostrou eficaz neste trabalho. Além de dinamizar e tratar do grande problema no ensino tradicional de física, levando os alunos a se interessarem mais pela disciplina e estimular a busca contínua pelo conhecimento. 
O principal objetivo do trabalho era a melhoria nos índices de aproveitamento dos alunos na disciplina de Física e o incentivo à busca pelo conhecimento, principalmente de forma autossuficiente, através da metodologia aplicada. Dessa forma, os resultados encontrados nas falas dos alunos e nos índices de aproveitamento (mais de 60\%) mostraram resultado satisfatório e estimulante.

Obviamente que essa metodologia não exclui ou substitui uma aula tradicional e outros existentes, mas surge como uma possibilidade de se trabalhar em conjunto com outros métodos.

Sabemos também que para aplicar o método é necessária uma certa estrutura com computadores, internet e outros. Entretanto, reforçamos que a plataforma de avaliação pode facilmente ser substituída por outras metodologias, como: Flash cards, questionários e outros já citados.

Por fim, vale salientar que o tema tratado teve como objetivo abordar os conceitos e leis da Física que norteiam o estudo da Eletrodinâmica por meio da metodologia Peer Instruction usando MCs no software cmap tools. Apesar de terem sido apresentados os conceitos e as equações matemáticas baseadas na: (a) $1^{a}$ lei de Ohm em circuitos elétricos numa associação de resistores em série e paralelo construído no circuit lab, (b) $2^{a}$ lei de ohm. Também demos enfoque na parte do desenvolvimento histórico e tecnológico.

\section{REFERÊNCIAS}

ARAUJO, A. V. R. de; SILVA, E. S.; JESUS, V. L. B. de; OLIVEIRA, A. L. de. Uma associação do método Peer Instruction com circuitos elétricos em contextos de aprendizagem ativa. Rev. Bras. Ens. Fís., v. 39, n. 2, p. e2401 (1-6), 2017.

ARAUJO, I. S.; MAZUR, E. Instrução pelos Colegas e Ensino sob Medida: Uma Proposta para o Engajamento dos Alunos no Processo de Ensino-Aprendizagem de Física. Cad. Bras. Ens. Fís., v. 30, n. 2, p. 362-384, 2013.

BERBEL, N. A. N. As metodologias ativas e a promoção da autonomia de estudantes. Semina: Ciências Sociais e Humanas, v. 32, n. 1, p. 25-40, 2011.

BETANCOURT, J. F.; PERDOMO, A. P. El uso de la plataforma Moodle con recursos infotecnológicos interactivos en la docencia en la Física. Una experiência en el curso de Física Moderna II. Lat. Am. J. Phys. Educ., v. 2, n. 3, p. 284-288, 2008.

PEÑA, A. V.; PESSOA DE CARVALHO, A. M; PRAIA, J; GIL PEREZ, D; CACHAPUZ, A. F. (Orgs.). A Necessária Renovação do Ensino de Ciências. 3a. ed., São Paulo: Cortez, 2011.

CROUCH. C. H.; WATKINS, J.; FAGEN, A. P.; MAZUR, E. Peer Instruction: Engaging Students One-on-One, All At Once. Research-Based Reform of University Physics, v.1, p. 1-55, 2007.

CUMMINGS, K.; ROBERTS, S. G. A Study of Peer Instruction Methods with High School 
Physics Students. AIP Conference Proceedings, v. 1064, p. 103-106, 2008.

DELIZOICOV, D.; ANGOTTI, J. A.; PERNAMBUCO, M. M. Ensino de Ciências: fundamentos e métodos. São Paulo: Cortez, 2002.

GOMES, L. C.; BELLINI, L. M. Uma revisão sobre aspectos fundamentais da teoria de Piaget: possíveis implicações para o ensino de física. Rev. Bras. Ens. Fís., v. 31, n. 2, p. 23011-230110, 2009.

HAKE, R. R. Interactive-engagement versus traditional methods: A six-thousand-student survey of mechanics test data for introductory physics courses. Am. J. Phys., v. 66, n. 1, p. 64-74, 1998.

HIGA, I.; de OLIVEIRA, O. B. A experimentação nas pesquisas sobre o ensino de Física. Educar em revista. v. 28, n. 44, p. 75-92, 2012.

KIELT, E. D.; da SILVA, S. C. R; MIQUELIN, A. F. Implementação de um aplicativo para smartphones como sistema de votação em aulas de Física com Peer Instruction. Rev. Bras. Ens. Fís., v. 39, n. 4, p. e4405 (1-8), 2017.

LASRY, N.; MAZUR, E.; WATKINS, J. Peer Instruction: From Harvard to the two-year college. Am. J. Phys., v.76, n. 11, p. 1066-1069, 2008.

LARA,A.L.; MANCIA, L. B.; SABCHUK, L.; ALMEIDA PINTO, A. E.; SAKAGUT, P. M. Y. Ensino de física mediado por tecnologias de informação e comunicação: um relato de experiência. In: XX SIMPÓSIO NACIONAL DE ENSINO DE FÍSICA - SNEF. São Paulo, 2013.

MARCOM. G. S. O enem como indicador qualitativo do ensino: uma aplicação às questões de física. Dissertação (mestrado em Ensino de Ciências e Matemática) - Faculdade de Educação, Universidade Estadual de Campinas, SP: 2015.

MAZUR, E., Peer Instruction: A User's Manual, Prentice Hall, Upper Saddle River, NJ, 1997.

MOREIRA, M. A. A teoria da aprendizagem significativa de Ausubel. São Paulo: Editora Pedagógica e Universitária, 1999.

MOREIRA, M. A. A teoria dos campos conceituais de Vergnaud, o ensino de ciências e a investigação nesta área. Investigações em Ensino de Ciências, v. 7, p. 7-29, 2002.

MOREIRA, M. A. Mapas conceituais e aprendizagem significativa. São Paulo: Centauro, 2010.

MOREIRA, M. A. O que é afinal aprendizagem significativa? Instituto de Física - UFRGS. Porto Alegre: p. 1-27, 2012. 
OLIVEIRA, V.; ELIANE, A. V.; ARAUJO, I. S. Relato de experiência com os métodos Ensino sob Medida (Just-in-Time Teaching) e Instrução pelos Colegas ( Peer Instruction) para o Ensino de Tópicos de Eletromagnetismo no nível médio. Cad. Bras. Ens. Fís., v. 32, n. 1, p. 180-206, 2015.

PIAGET, J. Reading in Child Behavior and Development, edited by C.S. Lavattelly and F. Stendler (Hartcourt Brace Janovich, New York, 1972). Tradução de Paulo Francisco Slomp, disponível em http://educadi.psico.ufrgs.br/servicos/listas/ppg- cognitiva/doc00000.doc. Acesso em 12/09/2018.

RICARDO, E. C.; FREIRE, J. C. A. A concepção dos alunos sobre a física do ensino médio: um estudo exploratório. Rev. Bras. Ens. Fís., v. 29, n. 2, p. 251-266, 2007.

STUDART, N. Inovando a Ensinagem de Física com Metodologias Ativas. Revista do Professor de Física, v. 3, n. 3, p. 1-24, 2019. 